\title{
Rock Slope Stability Analysis Software Based On Fuzzy Mathematics
}

\section{Theory}

\author{
Meng-fei Xu1,a, An-nan Jiang ${ }^{1, b}$, Xun Tian², Xing-cang Yao ${ }^{3}$ \\ ${ }^{1}$ Institute of Road and Bridge Engineering, Dalian Maritime University, Dalian 116026, China; \\ ${ }^{2}$ China Road and Bridge Corporation, Beijing 100011, China; \\ ${ }^{3}$ China Construction Eight Engineering Division.CORP.LTD Dalian branch company,No.237,Gorky \\ road,Dalian 116021,China; \\ a email:824599159@qq.com bemail:jiangannan@163.com
}

Keywords: rock slope information database,design of slope angle,evaluation of rock slope stability Abstract: A rock slope stability analysis software was developed through which data information of rock slope can be managed scientifically, rock slope angle can be designed reasonable. An evaluation mode of rock slope stability was set up on the basis of fuzzy mathematics theory, depend on which the stability of rock slope can be evaluated effectively and conveniently.The software is meaningful to the safety of rock slope engineering progress

\section{Introduction}

Sixty-nine percents of the country's territory is mountainous in China in which slope problems was account for a large proportion ${ }^{[1]}$.So, to manage the information of slope scientifically and evaluate the stability of rock reasonable and effectively became an urgent problem to be solved.In addition, the traditional methods, such as limiting equilibrium method and strength reduction method, are difficult to be applied in practical engineering. To solve above problems, Visual Studio 2010 was chose as development platform,c\# as development language and Access as backend database to develop a software which combines database management model and rock stability evaluation model to promote the safety of slope engineering construction.

\section{The composition of the software and database structure}

The software is composed of three models, which is rock slope information database management model,the design of rock slope angle model and evaluation of rock slope stability model as shown in Fig. 1.The rock slope database consists of 40 fields.

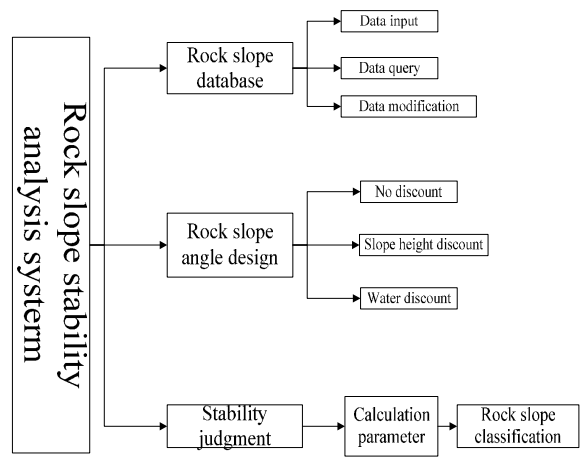

Fig.1 system composition 


\section{Design of rock slope angle}

In rock slope problem, the design of rock slope is a vital link. Research showed that ${ }^{[2]}$, the $R Q$ value which is expressed by the product of rock rebound value $R$ and integrity coefficient $I_{c}$ has a good correlation with the rock slope angle $\alpha$ shown in Eq. 1:

$\alpha=-40+38 \lg R Q$

where, $R Q$ is rock mass quality, $R Q=R I_{c}, R$ is the rock rebound value, $I_{c}$ is integrity coefficient shown in Eq. 2:

$$
I_{c}=\sum_{i=1}^{N} a_{i} g_{i}\left(x_{i}\right)
$$

Where, $a_{i}$ is the weight of factors; $x_{i}$ is the parameter of rock mass structure characteristic, which includes the number of joint sets, extensions, density, combination condition and size of structure face; $g_{i}\left(x_{i}\right)$ is the contribution value of all factors.

For rock mass ${ }^{[3]}$ :

$$
I_{c}=a_{1} g_{1}(n)+a_{2} g_{2}(f)+a_{3} g_{3}(l)+a_{4} g_{4}(D)+a_{5} g_{5}(C)+a_{6} g_{6}(t)
$$

where, $n, f, l, D, C, t$ is number of joints sets, density, extension length, lumpiness, combination condition and layer thickness; all the factors are the average or comprehensive value of whole slope rock mass, which express the characteristic of rock slope structure.

In the practical calculation, the value of each factor contribution can be affirmed as shown in Table 1.

\begin{tabular}{|c|c|c|c|c|c|c|c|c|c|}
\hline$g_{1}(n)$ & 100 & 70 & 50 & 30 & 20 & 10 & 5 & & \\
\hline$f($ strips $/ \mathrm{m})$ & 0 & $<0.2$ & $0.2 \sim 0.5$ & $0.5 \sim 2$ & $2 \sim 5$ & $5 \sim 10$ & $10 \sim 20$ & $>20$ & \\
\hline$g_{2}(f)$ & 100 & 90 & 80 & 50 & 40 & 10 & 5 & 0 & \\
\hline$L(m)$ & 0 & $0 \sim 1$ & $1 \sim 2$ & $2 \sim 5$ & $5 \sim 10$ & $10 \sim 20$ & $>20$ & & \\
\hline$g_{3}(l)$ & 100 & 80 & 70 & 40 & 30 & 10 & 0 & & \\
\hline$D(m)$ & $\infty$ & $>10$ & $10 \sim 5$ & $5 \sim 1$ & $1 \sim 0.5$ & $0.5 \sim 0.1$ & $0.1 \sim 0.05$ & $<0.05$ & \\
\hline$g_{4}(D)$ & 100 & 80 & 55 & 40 & 10 & 5 & 3 & 0 & \\
\hline$C$ & $\begin{array}{c}\text { excelle } \\
\mathrm{nt}\end{array}$ & well & normal & bad & Very poor & & & & \\
\hline$g_{5}(C)$ & 100 & 70 & 50 & 30 & 0 & & & & \\
\hline $\mathrm{t}(\mathrm{m})$ & $\infty$ & $>5$ & $5 \sim 1$ & $1 \sim 0.5$ & $0.5 \sim 0.1$ & $0.1 \sim 0.05$ & $0.05 \sim 0.01$ & $0.01 \sim 0.0005$ & $<0.005$ \\
\hline$g_{6}(t)$ & 100 & 85 & 60 & 35 & 10 & 5 & 3 & 1 & 0 \\
\hline
\end{tabular}

Table 1 Value of each factor contribution

The height of rock slope is an important factor that influences $\alpha$.So the reduction coefficient caused by height $H$ should be taken into consideration when $H \geqq 20$ as in Eq. 4 .

$$
\alpha=\arctan \left[\gamma_{H} \cdot \tan (-40+38 \lg R Q)\right]
$$

The value of $\gamma_{H}$ is shown in Table 2.

\begin{tabular}{ccccc}
\multicolumn{5}{c}{ Table 2 value of $\gamma_{H}$} \\
\hline$H(\mathrm{~m})$ & $<20$ & $20-25$ & $25-35$ & $>35$ \\
\hline$\gamma_{H}$ & 1 & 0.85 & 0.7 & 0.6 \\
\hline
\end{tabular}

$\mathrm{The}^{[4]}$ reduction coefficient of water consists of the weathering degrees which is closely related to the water, water level and filling degree as shown in Eq. 5. 
$\alpha=-40+38 \lg \left(\gamma_{w} \times R Q\right)$

where $\gamma_{\omega}=(\mathrm{C} 1+\mathrm{C} 2+\mathrm{C} 3) / 3, \mathrm{C} 1$ is the weathering degrees, $\mathrm{C} 2$ expresses water level and $\mathrm{C} 3$ is filling degree. The value of $\mathrm{C} 1, \mathrm{C} 2$ and $\mathrm{C} 3$ is shown in Table 3.

Table 3 Degrees of rock slope stability

\begin{tabular}{ccccc}
\hline degree & I & II & III & IV \\
\hline Weathering degree & Non-weathering & Tiny weathering & Quit heavy & Most serious \\
& 1 & 0.85 & 0.70 & 0.55 \\
Water level & Dry & Wet & Dripping & Linear flow \\
& 1 & 0.9 & 0.75 & 0.60 \\
Filling degree & Non-filling & Slightly-filling & filling & Full filling \\
& 1 & 0.85 & 0.70 & 0.55 \\
\hline
\end{tabular}

\section{Model of rock slope evaluation based on fuzzy mathematics theory}

There are two methods to evaluate rock slope stability which is quantitative analysis and qualitative analysis. Quantitative analysis consists of graphical method and mathematics analysis method which is used to calculate safety factor or similar concept to evaluate rock slope stability. Besides, numerical calculation method was used to analysis the deformation characters and stress conditions of rock slope ${ }^{[5]}$. However, a large numbers of assumptions are needed and simplified in those methods, so that the results can only play a reference role in practical engineering. In recent years, fuzzy mathematics theory was used to evaluated rock slope stability because it is effectively to solve uncertainly, randomly and fuzzy problems like rock slope stability.

Fuzzy mathematics theory

Degree sets and factor sets are given to describe rock slope stability according to fuzzy mathematics theory as shown in Eq. 6 and Eq. 7.

$\mathbf{U}=\left(u_{1}, u_{2}, \mathrm{~L} \mathrm{~L} u_{n}\right)$

$\mathbf{V}=\left(v_{1}, v_{2}, \mathrm{~L} \mathbf{L} v_{n}\right)$

where $u_{n}$ is the influence factor that should be considered in rock slope stability; $v_{n}$ is the evaluation degree.

In a given samples, an sets $A(A \in U)$ is chose to express weight of influence factors.

$$
\mathbf{A}=\left(a_{1}, a_{2} \mathrm{LL} a_{n}\right)
$$

The appropriate membership function is chose to calculate the membership of each factors in different degrees to form the fuzzy matrix.

$$
\mathbf{R}=\left|\begin{array}{cccc}
r_{11} & r_{12} & \mathrm{~L} & r_{1 m} \\
r_{21} & r_{22} & \mathrm{~L} & r_{2 m} \\
\mathrm{M} & \mathrm{M} & \mathrm{M} & \mathrm{M} \\
r_{n 1} & r_{n 2} & \mathrm{~L} & r_{n m}
\end{array}\right| \begin{gathered}
\text { factors } \\
\downarrow
\end{gathered}
$$

where $r_{i j}$ expresses the membership of $j$ factors in $i$ degrees when it has a constant value. So, the evaluation result of samples $\mathbf{B}(\mathbf{B} \in \mathbf{V})$ can be expressed in Eq. 10 . 
$\mathbf{B}=\mathbf{A} \cdot \mathbf{R}$

The classification of rock slope and calculating parameters

Rock slope can be classified into three degrees ${ }^{[6]}$, which is I (stable), II (basically stable), III (unstable) according to the rock slope stability during design, constructing and operating and its engineering treatment measures as shown in Table 4.

Table 4 Classification of rock slope

\begin{tabular}{|c|c|c|c|}
\hline items & $\begin{array}{c}\text { I } \\
\text { Stable }\end{array}$ & $\begin{array}{c}\text { II } \\
\text { Basically stable }\end{array}$ & $\begin{array}{c}\text { III } \\
\text { Unstable }\end{array}$ \\
\hline Time & $\begin{array}{l}\text { Stable after } \\
\text { excavating }\end{array}$ & $\begin{array}{l}\text { incidental } \\
\text { processing }\end{array}$ & Unstable after excavating \\
\hline Failure types & $\begin{array}{l}\text { Non-failure, } \\
\text { peeled off, } \\
\text { a small amount of } \\
\text { shattered }\end{array}$ & $\begin{array}{l}\text { Basically stable } \\
\text { chipping off } \\
\text { partial slump }\end{array}$ & $\begin{array}{l}\text { Large slump, } \\
\text { a large number of sliding, } \\
\text { bedding sliding, } \\
\text { toppling }\end{array}$ \\
\hline Engineering measures & Excavating directly & $\begin{array}{l}\text { Spray anchor, } \\
\text { jointing,grouting,p } \\
\text { atching,revetment, } \\
\text { locally supported }\end{array}$ & $\begin{array}{l}\text { barricade, opencut tunnel } \\
\text { Moving away rocks, } \\
\text { Anchored pile,reroute }\end{array}$ \\
\hline
\end{tabular}

Rock slope stability is affected by many factors such as geographic and geomorphic conditions, lithology, structure, hydrogeology and so on. Influence factors shown in Table 5 are chose as criterion to be quantified as parameters that can be get easily in engineering application to evaluate the stability of rock slope.

Table 5 calculating parameters and influence factors

\begin{tabular}{|c|c|c|c|c|c|}
\hline $\begin{array}{l}\text { Calculating } \\
\text { parameters }\end{array}$ & $R$ & $I_{c}$ & $G P$ & $G K$ & $N$ \\
\hline $\begin{array}{l}\text { Influence } \\
\text { factors }\end{array}$ & $\begin{array}{l}\text { Lithology, } \\
\text { Uniaxial } \\
\text { compressive } \\
\text { strength, } \\
\text { Degree of } \\
\text { weathering }\end{array}$ & $\begin{array}{l}\text { Joints numbers, } \\
\text { Density, } \\
\text { Stretch, } \\
\text { Filling degrees, } \\
\text { Combination } \\
\text { conditions }\end{array}$ & $\begin{array}{l}\text { Extension } \\
\text { of joints, } \\
\text { Height of } \\
\text { rock slope }\end{array}$ & $\begin{array}{l}J R C \text { (coarse degrees of } \\
\text { joints), } \\
\text { Joints attitude } \\
\text { (bedding,schistosity), } \\
\text { Gradient of rock slope }\end{array}$ & $\begin{array}{l}\text { Total number of } \\
\text { sliding blocks } \\
\text { whose } K<1\end{array}$ \\
\hline
\end{tabular}

The rock rebound value $R$ and integrity coefficient $I_{c}$ was discussed above. The value of $G P$ and $G K$ will be discussed as below.

Comprehensive relative cut-through degrees $G P$

For joints $J_{i}$, its relative cut-through degrees is shown in Eq. 11 when the stability coefficient of structure body which is cut by the joints and exposes out of the rock slope is less than 1 . $G P=\frac{1}{n} \sum P_{i}=\frac{1}{n} \sum \frac{L_{i}}{H}$

where $H$ is the height of rock slope. For other conditions, $P_{i}=0$. For bedding, $P_{i}=1$. The arithmetic means value of all $P i$ is taken as comprehensive relative cut-through degrees of the whole rock slope where if a joint constitute a multiple blocks at the same time, it should be calculated repeatedly.

Comprehensive stability coefficient $G K$

According to limit equilibrium theory, when $\left|\varphi_{s}-\varphi_{f}\right| \leq 30, \alpha>\beta_{f}$, the stability coefficient $K_{f}$ can be calculated as below. 


$$
K_{f}=\frac{\tan \varphi_{0}}{\tan \beta_{f}}
$$

where $\varphi_{\mathrm{s}}$ is slope direction; $\alpha$ is slope angle; $\varphi_{f}$ is inclination of structure plane; $\beta_{f}$ is dip angle; $\tan \varphi_{0}$ is friction coefficient.

When $\left|\varphi_{s}-\varphi_{w}\right| \leq 60, \alpha<\beta_{w}$, the wedge stability coefficient can be calculated in Eq. 13.

$$
K_{w}=\frac{\cos \theta_{1} \tan \varphi_{2}+\cos \theta_{2} \tan \varphi_{1}}{\sin \left(\theta_{1}+\theta_{2}\right) \cdot \tan \beta_{w}}
$$

where $\varphi_{w}$ is inclination of double-faced body; $\beta_{w}$ is dip angle; $\theta_{1}, \theta_{2}$ is the angles between faces of double-faced body and vertical plane across the intersection line.

For Eq. 12 and Eq. 13:

$\varphi_{i}=\varphi_{b}+J R C_{i} \log \frac{\sigma_{j}}{\sigma_{n}}$

where $J R C$ is coarse degrees of structure plane calculated by Eq. 15

$J R C=0.36 n+0.73 H$

$n$ is the number of convex body on structure plane in $50 \mathrm{~cm} ; H$ is the height of convex body.

In most cases, there is $0.5<\log \frac{\sigma_{j}}{\sigma_{n}}<2$; for low height rock slope there is $\log \frac{\sigma_{j}}{\sigma_{n}}=1$, so Eq. 16 can be changed to Eq. 17.

$\varphi_{i}=\varphi_{b}+J R C_{i}$

So, the comprehensive stability coefficient $G K$ of whole rock slope can be calculated in Eq. 17 .

$$
G K= \begin{cases}\frac{1}{n}\left(\sum K_{f}+\sum K_{\omega}\right) & \left(K_{f}, K_{\omega}<1\right) \\ \min \left(K_{f}, K_{\omega}\right) & \left(K_{f}, K_{\omega} \geq 1\right)\end{cases}
$$

Membership function and weight coefficient

The membership function should be construct to calculate the value of each influence factor in different degrees. The common methods to construct membership function are fuzzy statistical method, Delphi and Relative selection method. This paper built the membership function according to the statistics of 147 rock slope samples throughout the country using polynomial fitting as shown in reference[7].

The weight coefficient is difference as the calculating parameters changes. The value of weight coefficient is shown in Table 6 according to the research and trial.

Table 6 Value of weight coefficient

\begin{tabular}{cc}
\hline Calculating parameters & $A=\left(R, I_{c}, G P, G K, N\right)$ \\
\hline$R<30$ & $A=(5,4,0.5,0.5,0)$ \\
$G K \triangleq 4, R \triangleq 30$ & $A=(2,3,0.5,2,1)$ \\
$1 \cong G K<4, R \triangleq 30$ & $A=(3,5,0.2,1.5,0.3)$ \\
$G K<1,0.15<G P<0.55, R \triangleq 30$ & $A=(2,3,1.5,1.5,2)$ \\
$G K<1, G P<0.15, R \triangleq 30$ & $A=(3,4,1.5,1,1.5)$ \\
$G K<1, G P \cong 0.55, R \triangleq 30$ & $A=(1,1.5,3,2,1.5)$ \\
\hline
\end{tabular}

neering application

Fusong tunnel is located in Baisha city in eastern part of Jinlin province where the exposure stratum mainly consists of Jurassic lacustrine facies clastic rock, andesite and basalt. On the location of which stake mark is DK276+700, the ground evaluation is about $548 \mathrm{~m}$ and the hills 
evaluation declines gradually to $435 \mathrm{~m}$ where the slope angle is about 38 degree. To evaluate stability of the rock slope, relevant parameters are calculated through the method discussed above: $R=40, I_{c}=23, G P=5.37, G K=0.672$ and $N=1$. The value of weight coefficient is chosen according to Table $6, A=(1,1.5,3,2,1.5)$. The fuzzy matrix is built as Eq. 18.

According to Eq. 10:

$$
\mathbf{B}=\mathbf{A} \cdot \mathbf{R}=(1,1.5,3,2,1.5) \cdot\left|\begin{array}{ccc}
32.64 & 15.72 & 24.16 \\
19.31 & 25.78 & 24.60 \\
15.42 & 23.53 & 1.0 \\
0 & 11.58 & 13.77 \\
17 & 32 & 0
\end{array}\right|=(133.37,196.14,91.60)
$$

Normalizing B :

$$
\mathbf{B}=(31.7 \%, 46.58 \%, 21.72 \%)
$$

So, the evaluation of rock slope stability degree is II (basically stable) which is in line with the actual meaning the theory is correctly. The result means some measures should be taken to strengthening the slope such as spray anchor, jointing and so on shown in Table 5.

In process of construction, the calculation can be done conveniently and accurately by software after typing into the parameters as shown in Fig. 2.

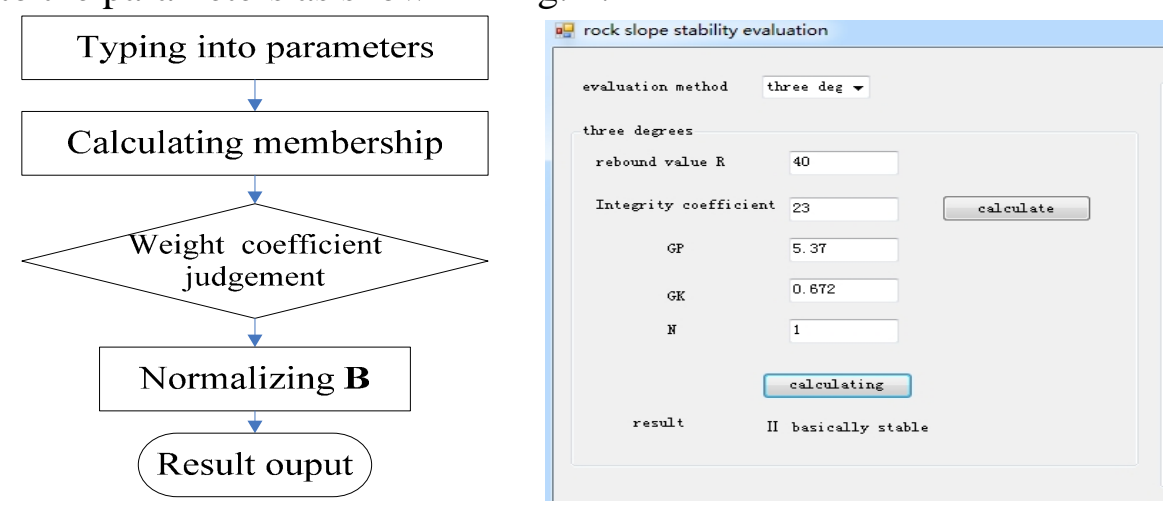

Fig. 2 Computation flow of rock slope stability evaluation

\section{Conclusions}

A software used for evaluating the rock slope stability was developed which implements following functions:

1.Access backend database is established to manage the rock slope information in scientific method.

2.The reduction coefficient caused by underground water and rock slope height is quantified to compile the model to design rock slope angle.

3.The program to evaluate rock slope stability is compiled based on fuzz mathematics theory to evaluate rock slope stability conveniently and effectively.

\section{Acknowledgements}

This work was financially supported by the National Natural Science Foundation (51678101 and 51578447).

\section{References}

[1] Wang Zhe,Yi Facheng. China Mining Magazine,2016,15(10),47-50.(in Chinese)

[2] Xie Qiang. China Journal of Highway and Transport,2000,13(2),24-26.(in Chinese) 
[3] Jiang Jueguang,Qian Huiguo.Journal of Southwest Jiaotong University,1991,(2),23-29. (in Chinese)

[4] Yin Xiaohong,Liu Qingyuan. HUNAN Metallurgy,2000,(5),31-33.(in Chinese)

[5] Li Jing. Chinese Journal of Geotechnical Engineering,1998,20(4),40-43.(in Chinese)

[6] Wu Aiqing,Ding Xiuli and Lu Bo,et al..Chinese Journal of Rock Mechanics and Engineering, 2008,27(4),664-672.(in Chinese)

[7] JiangJueguang.Railwayrockslope.Beijing:China railway publishing house,1997:119-130.(in Chinese) 